\title{
Design, Build and Test an Unmanned Air Vehicle
}

\author{
Wail I. Harasani \\ Faculty of Engineering, King Abdulaziz University \\ Jeddah, Saudi Arabia \\ wharasani@kau.edu.sa
}

\begin{abstract}
The aim of this project is to design, build and test an unmanned aircraft. The design of the air vehicle is characterized by its twin boom, high wing, zero sweep angle layout and 2.9 meter span.
\end{abstract}

Aerodynamic load calculations, stress analysis, performance, stability, and control calculations have been performed. The analysis was carried out by using more than one commercial design software, such as TORNADO SOFTWARE for aerodynamics, ANSYS for stress analysis, and EXCEL spreadsheet for the performance and stability derivatives. The sizing and design was performed by the author.

The project has the following stage phases: Theoretical design. This includes calculation of the aircraft parameters and computer simulation of the unmanned aircraft in different flight conditions; acquiring materials and tools; manufacturing the main body of the aircraft; assembly of the aircraft; testing the autopilot; ground testing; and flight testing.

Finally, this report documents the different phases of the project, leading to the flight test that has been carried out to confirm the results generated.

Keywords: Aircraft design, UAV, Aircraft Analysis.

\section{Introduction}

Unmanned Air Vehicles (UAVs) are self or remotely piloted aircrafts that can carry cameras, sensors, communications equipment or other payloads. Self piloted means using the autopilot system, which is a system placed on the aircraft and allow automatic control of flight surfaces and propulsion ${ }^{[1]}$. 
Based on the sizing, and the design of the aircraft that was designed by the author, this paper describes and documents the work done in different aspect of the design process for the project which led to the first flight test.

The King Abdulaziz University aircraft model configuration is characterized by its twin boom, high wing configuration for stability, zero sweep wing layout, with a flat bottom aerofoil wing, powered by a reciprocating engine, the model is equipped with the following systems:

- Reciprocating engine with directly coupled propeller

- De-Coupled Flight Control System (DCFCS)

- Onboard Video Camera System.

- Ground Station

- Parameter Identification System

- Electrical System

\section{Airframe}

The purpose of this section is to describe the design, analysis, and construction of the model aircraft shown in Fig. 1:

2.1 Wing

2.2 Fuselage and Tail Boom

2.3 Empennage

2.4 Landing gear
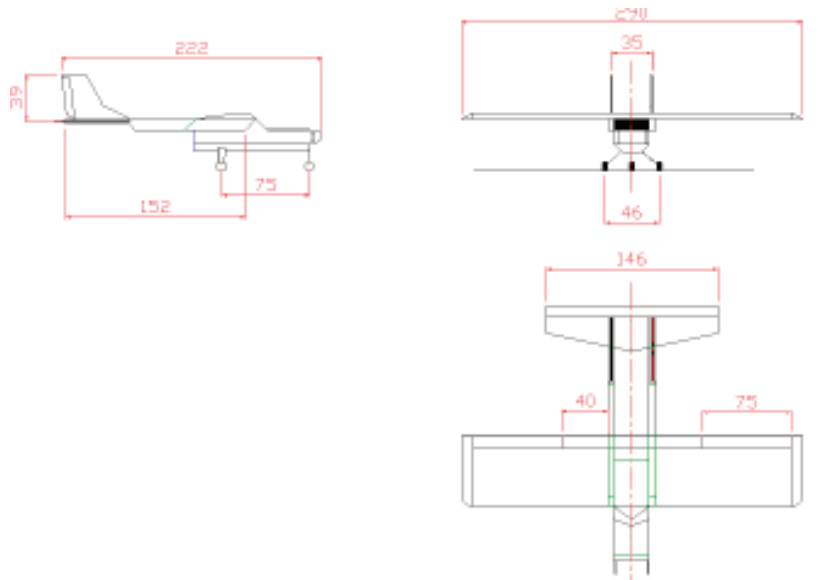

Fig. 1. Three views drawing of the aircraft. 


\subsection{Wing}

In this section the procedure for designing and analyzing the wing for the model are presented, depend on the data from Tables 1 and 2. The ultimate flight load factor was calculated to be $3 \mathrm{~g}$ 's. The aerodynamic load was calculated on the wing using TORNADO software as shown in Fig. 2.

The first case is when the plane is in the straight and level flight as shown in Fig. 2 with the pressure distribution on airplane without using flaps. Also, you can see here the maximum pressure will be in the leading edge of the wing and decrease backward to trailing edge.

The forces in this case is :

- Lifting force $=220 \mathrm{~N}$

- Drag force $=14 \mathrm{~N}$

Table 1. Flight condition data.

\begin{tabular}{|l|l|}
\hline Velocity $(\mathrm{V})$ & $30 \mathrm{~m} / \mathrm{s}$ \\
\hline Density $(\rho)$ & $1.225 \mathrm{~kg} / \mathrm{m}^{3}$ \\
\hline Pressure $(\mathrm{P})$ & $100375 \mathrm{~Pa}$ \\
\hline Temperature $(\mathrm{Ta})$ & $25^{\circ} \mathrm{C} / 298 \mathrm{k}$ \\
\hline
\end{tabular}

Table 2. Wing geometry.

\begin{tabular}{|l|l|}
\hline Wing Span (b) & $2.90 \mathrm{~m}$ \\
\hline Chord (c) & $0.6 \mathrm{~m}$ \\
\hline Wing Area (S) & $1.74 \mathrm{~m}^{2}$ \\
\hline Aspect Ratio (AR) & 4.83 \\
\hline Flap Area (Sf) & $0.04 \mathrm{~m}^{2}$ \\
\hline Aileron Area (Sa) & $0.075 \mathrm{~m}^{2}$ \\
\hline
\end{tabular}

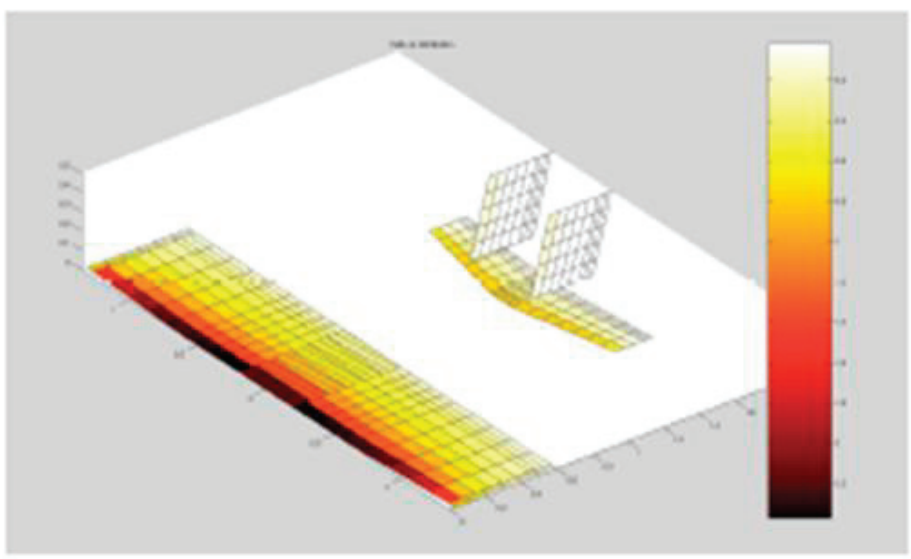

Fig. 2. Pressure distribution on airplane with disengaged flaps. 
A stress analysis was made using ANSYS. The wing was constructed by using balsa wood with a reinforced aluminum main spar (Fig. 3 and 4). The balsa wood material properties modulus of elasticity was assumed to be as $4.1 \mathrm{GPa}$ as given in Table 3, the result of the maximum deflection at the tip of the wing equals $6.3 \mathrm{~cm}$. For easy manufacturing a flat bottom airfoil was used for the wing section (i.e., CLARK YH).

Table 3. Material proprietes.

\begin{tabular}{|l|l|}
\hline Balsa wood Modulus of elasticity (Eb) & $4.1 \mathrm{GPa}$ \\
\hline Aluminum Modulus of elasticity (Ea) & $69 \mathrm{GPa}$ \\
\hline
\end{tabular}

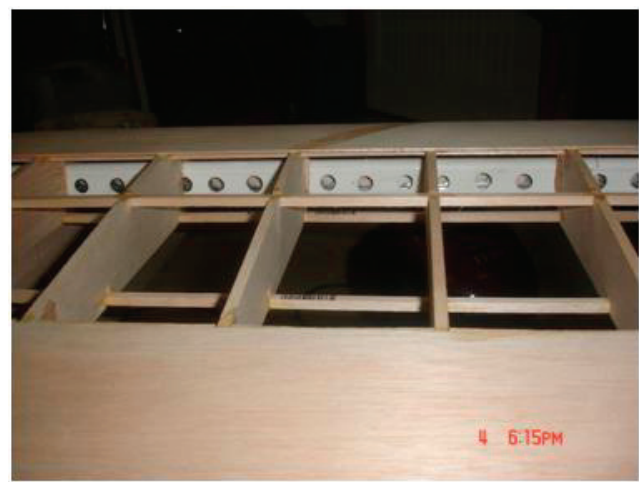

Fig. 3. Aluminum spar in the wing.

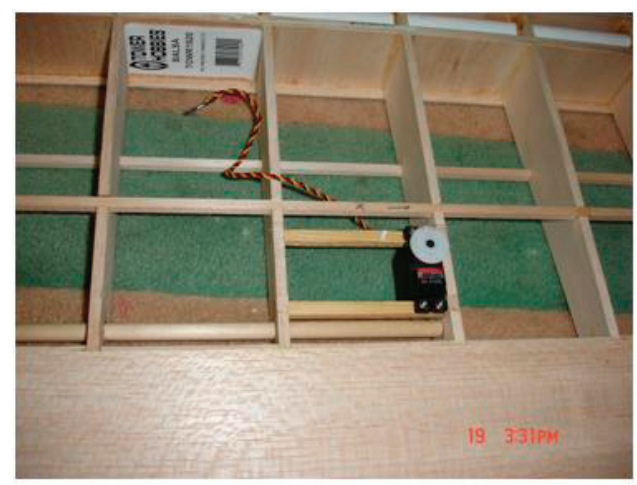

Fig. 4. Servo motor mounted to the wing.

\subsection{Fuselage and Tail Booms}

In this section a summary of the model design, analysis, and construction of the fuselage is presented. The fuselage and the tail booms are built into one single unit, fuselage and the tail boom was built entirely 
of balsa, and plywood wood. Plywood is used where the compression force of bolts needs to be resisted. The aerodynamic and stress analysis was made only for the wing section; the fuselage is designed to carry all the payload of the aircraft that includes the fuel tanks, batteries, the autopilot, etc. (Fig. 5 and 6).

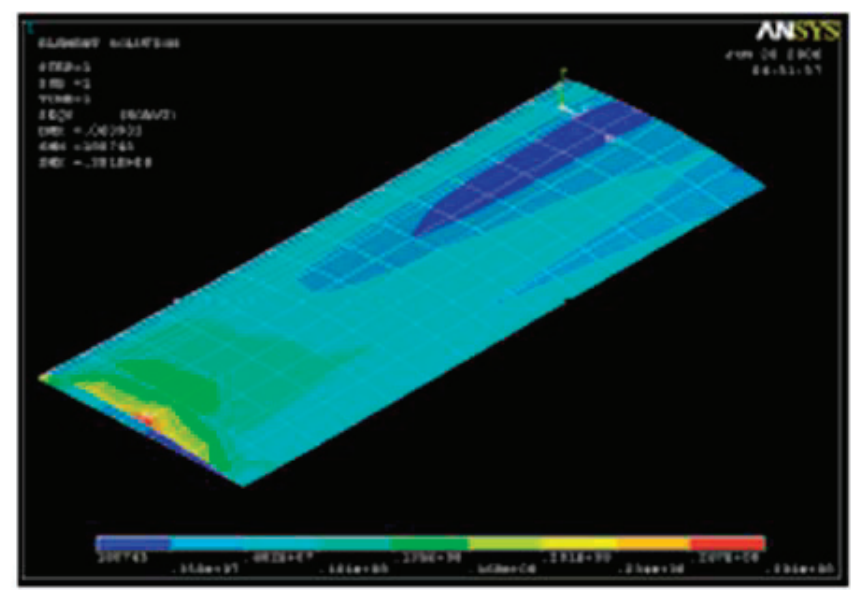

Fig. 5. Maximum and minimum stress at wing structure.

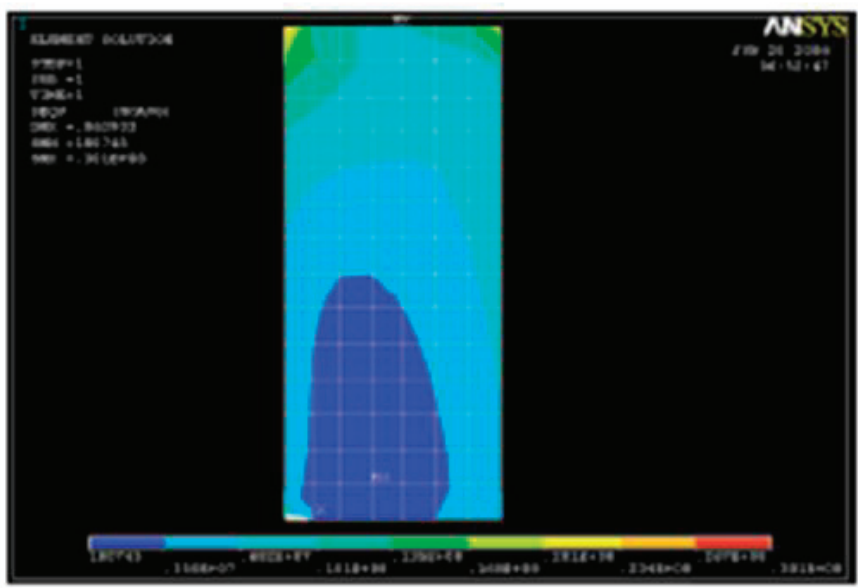

Fig. 6. Force distribution on the wing.

\subsection{Empennage}

In this section a summary of the model design, analysis, and construction of the empennage is presented. This includes:

- Horizontal tail. 
- Vertical tail.

- Attachment of the empennage surface to the tail boom

The empennage is built entirely of balsa, for simplicity a flat plat airfoil was used for both the vertical and horizontal tail (Fig. 7 and 8).

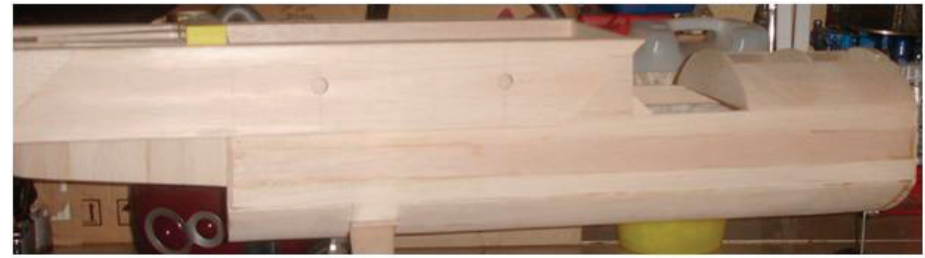

Fig. 7. Fuselage and the tail boom mounted .

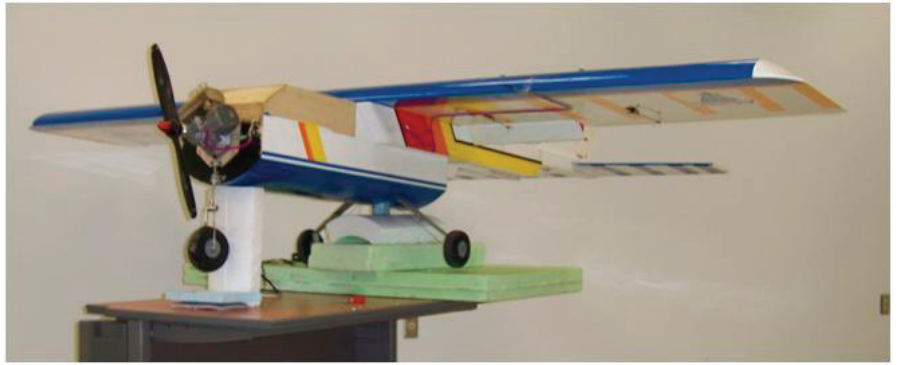

Fig. 8. Wing mounted on the fuselage.

\subsection{Landing Gear}

The landing gear is mounted to the fuselage as shown in Fig. 9, servo motor provides steering for the main landing, and is attached directly to a base in a fuselage, in which it controls both with the same servo the main landing gear and the rudder.

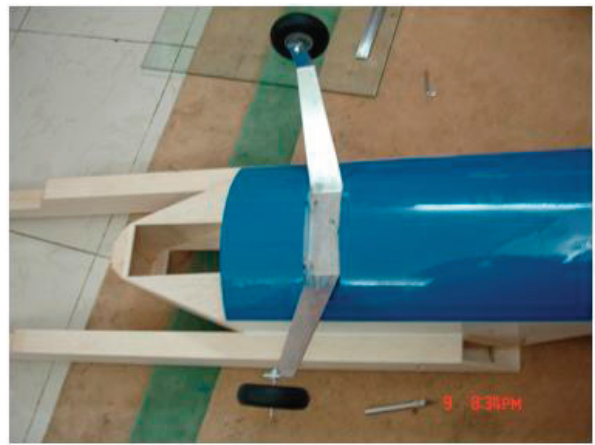

Fig. 9. Landing gear mounted on the fuselage. 


\section{Power Plant}

The purpose of this section is to present the specifications, integration, and the procedure for the model power plant.

\subsection{Selection Criteria}

In this section the selection criteria and specifications for the chosen system are presented.

Electric and piston, as well as turbine engine were considered for the module, the engine selection was

Based on the following criterion

- Engine Weight

- Power versus RPM

- Dimensions

- Cost

- Fuel type

\subsection{Engine Type}

The chosen engine has the following specifications:

Table 4. Engine selected data ${ }^{[3]}$.

\begin{tabular}{|l|c|}
\hline \multicolumn{1}{|c|}{ Engine Configuration } & \\
\hline Engine type & Single piston two stroke \\
\hline Horsepower & $3.7 \mathrm{HP}$ @ $12600 \mathrm{RPM}$ \\
\hline RPM & 2000 to $12600 \mathrm{RPM}$ \\
\hline Weight-Engine Alone & $1.94 \mathrm{lbs}(897 \mathrm{~g})$ \\
\hline Weight with muffler & $2.38 \mathrm{lbs}(1077 \mathrm{~g})$ \\
\hline Overall length & $117.5 \mathrm{~mm}(4.63 ")$ \\
\hline Width & $49 \mathrm{~mm}(1.93 ")$ \\
\hline Height & $117.5 \mathrm{~mm}(4.63 ")$ \\
\hline Fuel Type & Nitro \\
\hline Price & $\$ 150$ \\
\hline
\end{tabular}

\section{Weight, Aerodynamic, and Performance Characteristics}

The purpose of this section is to present the aerodynamic, weight, performance characteristics, and the stability derivatives for the aircraft.

4.1. Weight Characteristics 
4.2. Aerodynamic, and Performance Characteristics

\subsection{Weight Characteristics}

The total weight of the aircraft was $12 \mathrm{~kg}$, and the c.g. location was experimentally located.

Table 5. Aircraft weights.

\begin{tabular}{|l|l|l|}
\hline Fuel weight & 0.5 & $\mathrm{~kg}$ \\
\hline Aircraft weight & 12.0 & $\mathrm{~kg}$ \\
\hline CL max & 1.30 & \\
\hline
\end{tabular}

\subsection{Aerodynamic and Performance Characteristics}

The purpose of this section is to present the aircraft aerodynamic and performance characteristics. Table 6 shows a summary of some performance parameters ${ }^{[4]}$.

Note: aircraft mass includes all mass on the aircraft excluding the fuel mass.

\section{Stall Speed}

The stalling speed of the aircraft is the minimum speed the UAV that can produce lift at maximum lift coefficient $\mathrm{C}_{\mathrm{Lmax}}$, also it's the minimum speed in which flight is possible.

$$
V_{\text {stall }}=\sqrt{2 \frac{\left(\frac{W}{S}\right)}{\rho} / C L}
$$

Where:

W: Weight of the aircraft

S: Aircraft wing area

$\rho$ : Air density

$\mathrm{C}_{\text {Lmax }}$ : Maximum lift coefficient

$\mathrm{V}_{\text {stall: }}$ Staling speed

\section{Minimum Power}

Minimum power is defined as the least fuel consumption. Minimum power is desired to achieve the maximum time in flight. This is achieved by using multiplying the drag for minimum power conditions by velocity also in minimum power condition. Equations for velocity and drag in minimum power conditions are shown below the following equation: 
Table 6. Aircraft performance results.

\begin{tabular}{|l|l|l|}
\hline A/C \& GPS mass & 12.00 & $\mathrm{~kg}$ \\
\hline CLmax & 1.30 & \\
\hline Wing Loading W/S & 70.40 & $\mathrm{~N} / \mathrm{m}^{\wedge} 2$ \\
\hline Vstall & 9.40 & $\mathrm{~m} / \mathrm{s}$ \\
\hline A/C Take Off weight & 122.50 & $\mathrm{~N}$ \\
\hline GPS & 2.00 & $\mathrm{~kg}$ \\
\hline Auto pilot & 1.00 & $\mathrm{~kg}$ \\
\hline Power Avil & 3.0 & $\mathrm{BHp}$ \\
\hline Max L/D & 12.31 & \\
\hline CD min power & 0.08 & \\
\hline CL min power & 0.85 & \\
\hline L/D min power & 10.67 & \\
\hline Vmin power & 11.6 & $\mathrm{~m} / \mathrm{s}$ \\
\hline Vmin drag & 15.3 & $\mathrm{~m} / \mathrm{s}$ \\
\hline Max Range & 16.8 & $\mathrm{~km}$ \\
\hline Max Range With cam ,GPs ,AP & 12.6 & $\mathrm{~km}$ \\
\hline Max Endurance & 21.0 & $\mathrm{~min}$ \\
\hline Max Endurance with cam, GPS, AP & 13.8 & $\mathrm{~min}$ \\
\hline
\end{tabular}

$$
\begin{gathered}
P_{\min }=D_{m p} V_{m p} \\
V_{m p}=\sqrt{2 \frac{\left(\frac{W}{S}\right)}{\rho} / C_{L m p}} \\
C_{L m p}=\sqrt{\frac{3 C_{D O}}{K}} \\
D_{m p}=\frac{W}{\left(\frac{C_{L}}{C_{D}}\right)_{m p}} \\
\left(\frac{C_{L}}{C_{D}}\right)=\sqrt{\frac{C_{D O} \cdot K}{\left(C_{D}\right.}}
\end{gathered}
$$

Where:

$\mathrm{P}_{\text {min }}$ : Minimum power

$\mathrm{D}_{\mathrm{m}}$ : The drag of minimum power

$\mathrm{V}_{\mathrm{mp}}$ : The velocity of minimum power 
$\left(\mathrm{C}_{\mathrm{L}} / \mathrm{C}_{\mathrm{D}}\right)_{\mathrm{mp}}$ : Is lift over drag ratio at minimum power

\section{Range}

The total range is the distance an aircraft can fly between takeoff and landing, as limited by fuel capacity, which can be calculated as follows:

$$
R=\left(\frac{\eta}{c}\right)\left(\frac{C_{L}}{C_{D}}\right) \ln \left(\frac{W_{o}}{W_{1}}\right)
$$

\subsection{Stability and Control Derivatives}

The purpose of this section is to provide an overview of the stability and control analysis conducted on the aircraft.

Table 7 presents selected stability and control derivatives in approach. For comparative purposes, the stability and control derivative for the Cessna T-37 in the approach flight condition are also shown.

Stability of an aircraft is divided into two major groups, static and dynamic stability. Static stability is divided into two groups, longitudinal and directional.

\subsubsection{Longitudinal Static Stability}

Longitudinal stability in equation terms is denoted by $\mathrm{C}_{\mathrm{m} \alpha}$ (pitching moment coefficient for the wing depending on the angle of attack). The condition for longitudinal stability to be attained is when $\mathrm{C}_{\mathrm{m} \alpha}$ results are negative.

It is of interest to know the contribution of the wing, fuselage, tail, propulsion system, and the like, to the pitching moment and static stability characteristics of the airplane. In the following sections, each of the components will be considered separately. We will start by breaking down the airplane into its basic component, such as wing, horizontal tail and fuselage and propulsion unit.

For the airplane aerodynamic pitching moment $\mathrm{Cm}$

$$
C_{m}=C_{m o}+C_{m \alpha} \alpha+C_{m_{i h}} i_{h}+C_{m_{\delta e}} \delta_{e}
$$

Where:

$C_{m \alpha}=\partial C_{m} / \partial \alpha \quad$ Is the change in the airplane aerodynamic pitching moment coefficient due to a change in angle of attack. 
$C_{\text {mih }}=\partial C_{m} / \partial i_{h} \quad$ Is the change in the airplane aerodynamic pitching moment coefficient due to a change in the stabilizer incidence angle,

$C_{m \partial e}=\partial C_{m} / \partial \partial e \quad$ Is the change in the airplane aerodynamic pitching moment coefficient due to a change in the elevator angle,

$$
\begin{gathered}
C_{m o}=C_{m_{a c w f}}+C_{L_{o w f}}\left(x_{c g}-x_{a c w f}\right)+C_{L} \eta \frac{S_{h}}{S}\left(x_{a c}-x_{c g}\right) \varepsilon_{o} \\
C_{m \alpha}=C_{m_{\alpha} w f}\left(x_{c g}-x_{a c w f}\right)-C_{L \alpha h} \eta_{h} \frac{S_{h}}{S}\left(x_{c g h}-x_{a c}\right)\left(1-\frac{d \varepsilon}{d \alpha}\right) \\
C_{m i}=-C_{L \alpha h} \eta_{h} \frac{S_{h}}{S}\left(x_{a c h}-x_{c g}\right) \\
C_{m \delta e}=-C_{L \alpha h} \eta_{h} V_{h} \tau e
\end{gathered}
$$

For the airplane lift $C_{L}$

$$
C_{L}=C_{L o}+C_{L \alpha} \alpha+C_{L_{i h}} i_{h}+C_{L_{\delta e}} \delta_{e}
$$

Where:

$$
\begin{gathered}
C_{L \alpha}=\partial C_{m} / \partial \alpha \quad \begin{array}{l}
\text { Is the change in the airplane lift coefficient due } \\
\text { to a change in angle of attack. } \\
C_{L i h}=\partial C_{L} / \partial i_{h} \quad \begin{aligned}
\text { Is the change in the airplane lift coefficient due } \\
\text { to a change in the stabilizer incidence angle, }
\end{aligned} \\
\begin{aligned}
C_{L \partial e}=\partial C_{L} / \partial \partial e \quad & \text { Is the change in the airplane lift coefficient due } \\
& \text { to a change in the elevator angle, }
\end{aligned} \\
C_{L o}=C_{L o w f}-C_{L \alpha h} \eta_{h} \frac{S_{h}}{S} \varepsilon_{o}+C_{L o h} \\
C_{L \alpha}=C_{L_{\alpha} w f}+C_{L \alpha h} \eta_{h} \frac{S_{h}}{S}\left(1-\frac{d \varepsilon}{d \alpha}\right) \\
C_{L i}=C_{L \alpha h} \eta_{h} \frac{S_{h}}{S} \\
C_{L \delta e}=C_{L \alpha h} \eta_{h} \frac{S_{h}}{S} \tau_{e}
\end{array}
\end{gathered}
$$

$C_{L i h}=\partial C_{L} / \partial i_{h} \quad$ Is the change in the airplane lift coefficient due to a change in the stabilizer incidence angle,

$C_{L \partial e}=\partial C_{L} / \partial \partial e \quad$ Is the change in the airplane lift coefficient due 
Where:

$X c g$ : the distances from the wing leading edge to the aerodynamic center

$X a c$ : the distances from the wing leading edge to the center of gravity

$C:$ mean aerodynamic chord

$\eta$ : Tail efficiency

$V_{H}$ : The horizontal tail volume ratio and we get it from:

$\varepsilon$ : The downwash at zero angle of attack

$i_{w}$ : Wing incidence angle

$i_{t}:$ Tail incidence angle

$\frac{d \varepsilon}{d \alpha}$ : The rate of change of downwash angle with angle of attack

\subsubsection{Directional Stability}

Directional stability, also known as weathercock stability, concerns with the static stability of the aircraft about the Z-axis. With this kind of stability, the aircraft would tend to return to an equilibrium state when subjected to a yawing disturbance. In equation $\mathrm{C}_{\mathrm{n} \beta}$ denotes Directional stability terms. The condition for directional stability to be attained is when $\mathrm{C}_{\mathrm{n} \beta}$ results after calculation is positive.

For the airplane aerodynamic rolling moment $C_{l}$

$$
C_{l}=C_{l o}+C_{l \beta} \beta+C_{l \delta e} \delta_{e}+C_{l \delta r} \delta_{r}
$$

Where:

$C_{l \beta}=\partial C_{l} / \partial \beta \quad$ Is the change in the airplane rolling moment coefficient due to a change in the airplane sideslip angle $\beta$.

$C_{l \delta a}=\partial C_{l} / \partial \delta_{a} \quad$ Is the change in the airplane rolling moment coefficient due to a change in the aileron deflection angle,

$C_{l o r}=\partial C_{l} / \partial \delta r \quad$ Is the change in the airplane rolling moment coefficient due to a change in the rudder deflection, 
For the airplane aerodynamic side force coefficient $C y$

$$
C_{y}=C_{y o}+C_{y \beta} \beta+C_{y_{\delta e}} \delta_{e}+C_{y \delta r} \delta_{r}
$$

Where:

$C_{y \beta}=\partial C_{y} / \partial \beta \quad$ Is the change in the airplane side force coefficient due to a change in the airplane sideslip angle $\beta$.

$C_{y \delta a}=\partial C_{y} / \partial \delta_{a} \quad$ Is the change in the airplane side force coefficient due to a change in the aileron deflection angle,

$C_{y \partial r}=\partial C_{y} / \partial \delta r \quad$ Is the change in the airplane side force coefficient due to a change in the rudder deflection,

For the airplane aerodynamic yawing moment coefficient $C_{n}$

$$
C_{n}=C_{n o}+C_{n \beta} \beta+C_{n_{\delta e}} \delta_{e}+C_{n \delta r} \delta_{r}
$$

Where:

$C_{n \beta}=\partial C_{n} / \partial \beta \quad$ Is the change in the airplane yawing moment coefficient due to a change in the airplane sideslip angle $\beta$.

$C_{n \delta a}=\partial C_{n} / \partial \delta_{a} \quad$ Is the change in the airplane yawing moment coefficient due to a change in the aileron deflection angle,

$C_{n o r}=\partial C_{n y} / \partial \delta r \quad$ Is the change in the airplane yawing moment coefficient due to a change in the rudder deflection.

For dynamic stability we are concerned with the time history of the motion of the vehicle after a disturbance from its equilibrium point. It is important that after testing an aircraft for static stability to also test for dynamic stability, an aircraft with static stability does not necessarily mean that it is dynamically stable. The reduction of disturbance with time is desired, this is defined as dampened oscillation. Figure 10 shows a good example of types of stable and unstable dynamic motions. 


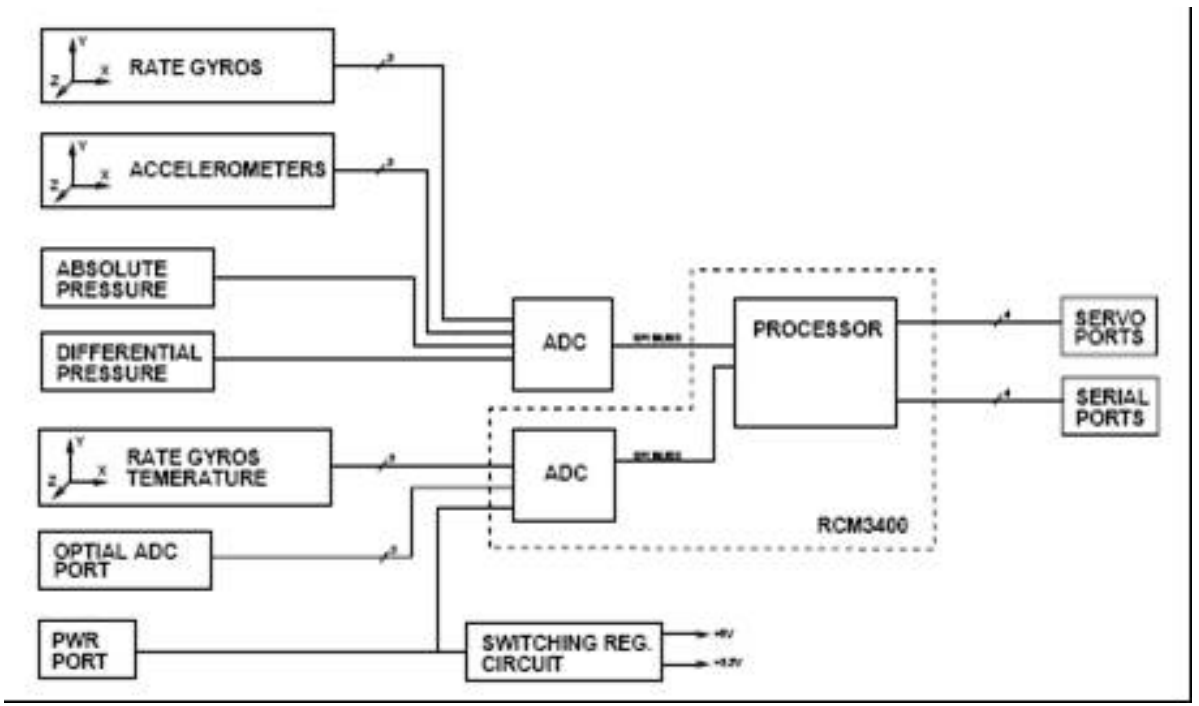

Fig. 10:. Block diagram of the flight control system(Kestrel) Ref. [7].

\subsubsection{Stability Derivatives}

The main stability derivatives are calculated, to compare the numbers generated with other aircraft, Table 7 below shows the numbers generated from KAU aircraft and the Cessna T-37A in approach.

Table 7. Selected stability and control derivatives for the aircraft.

\begin{tabular}{|c|c|c|}
\hline Coefficients & $\begin{array}{c}\text { KAU (UAV) } \\
\left(\text { Approach) }\left(\text { (rad }^{-1}\right)\right.\end{array}$ & $\begin{array}{l}\text { Cessna T-37A* } \\
(\text { Approach })\left(\text { rad }^{-1}\right)\end{array}$ \\
\hline $\mathrm{C}_{\mathrm{L} \alpha}$ & 5.4 & 4.64 \\
\hline $\mathrm{C}_{\mathrm{mq}}$ & -30 & -14 \\
\hline $\mathrm{C}_{\mathrm{m} \alpha}$ & -0.58 & -0.631 \\
\hline $\mathrm{C}_{1 \beta}$ & -0.02 & -0.0822 \\
\hline$C_{l p}$ & -0.53 & -0.458 \\
\hline $\mathrm{C}_{\mathrm{lr}}$ & 0.204 & 0.254 \\
\hline$C_{y \beta}$ & -0.612 & -0.303 \\
\hline$C_{n \beta}$ & 0.126 & 0.1095 \\
\hline$C_{n p}$ & -0.07 & -0.0768 \\
\hline $\mathrm{C}_{\mathrm{nr}}$ & -0.141 & -0.1613 \\
\hline $\mathrm{C}_{\text {Lie }}$ & 0.75 & 0.4 \\
\hline$C_{\text {móe }}$ & -2.3 & -1.05 \\
\hline $\mathrm{C}_{\mathrm{I \delta a}}$ & 0.17 & 0.1788 \\
\hline $\mathrm{C}_{\mathrm{n} \delta \mathrm{r}}$ & -0.05 & -0.0365 \\
\hline
\end{tabular}

* Reference [5] 


\section{Flight Control System}

In this section, a summary of the conventional control system for the aircraft is presented.

The aircraft utilized a standard, high quality radio control system designed for the use with model aircraft. The system consists of multi channel, digital transmitters, receivers and servos. Futaba system was considered for the design with 5 channels.

In a conventional flight control system, the longitudinal and lateral control mode, together with engine throttle setting, are coupled. In the proposed DCFCS, all of these modes will be de-coupled:

- Throttle will command speed

- Forward stick will command rate-of-climb

- Lateral stick will command rate-of-turn

The electrical system is relatively simple which consists of batteries, that supply the receivers, servos and the microcontroller.

The autopilot system consists of the following:

\section{I: Six Type of Sensors}

1. 3-axis Rate Gyros

2. 3-axis Accelerometers

3. Absolute Pressure sensor to measure the altitude

4. Differential Pressure Sensor to measure airspeed

5. 3- axis Magnetometers

6. GPS

II: A Microcontroller: That reads the data from the sensors and according to its program it will send signals to the servo motors to follow its calculated mission.

III: Servo Motors: That:

1. Moves the aileron to roll

2. Moves the elevator to pitch

3. Moves the rudder to yaw

4. Change throttle for speed

The Autopilot component that consists of the microcontroller computer, receiver, transmitter, and the virtual cockpit was bought from Procerus Technologies ${ }^{[6]}$. 
To program the microcontroller software, it had to undergo tasting stages, involves debugging, stepping over the program in a line by line fashion, involves grand testing. In order to ensure the proper operation of the remaining code, the aircraft had to be checked and different parameters had to be tuned in flight.

Note: component, programming, and wiring specifications are not listed, and further description for the control system is given in Ref. [6].

\section{Flight Testing}

Safety guidelines have been established to ensure the safety of the staff and by-standers near the test site, which consists of

- Pre-flight check procedures

- Definitions of the danger and safety zones

- Safety equipment

\section{Ground Testing}

The ground test consists of the following tests:

Steering test: To ensure the nose gear has sufficient steering power for the ground maneuvers.

Servo test: To ensure that all servos are working.

Engine test: To ensure that the engine is working.

\section{Flight Test}

Flight Test I: The first test flight was only conducted by flying the aircraft by using only radio control, that is to check the aircraft structure, and performance

Flight Test II: Several flight tests of the aircraft was attempted on April 2008, at King Abdulaziz University Campus, to tune and test the autopilot system.. During high speed taxing, the model was lifted off the ground, fly and successfully land, after 4 successful flight tests the autopilot was completely tuned. The aircraft was able to cruise at $120 \mathrm{~m}$, with a speed of around $17 \mathrm{~m} / \mathrm{s}$. Onboard video camera had captured images of the university campus. Figure 11 demonstrates virtual cockpit interface $^{[6]}$. 


\section{Conclusions and Recommendations}

Trade-off activities across functional organization were routing and unfortunately, So were the weight growth, short of financial resources, and schedule delays. Nevertheless, structural integrity of the model was not compromised.

The author would recommend that the project to be continued, these activities will provide researches for advanced technologies for the next generation of general aviation UAS.

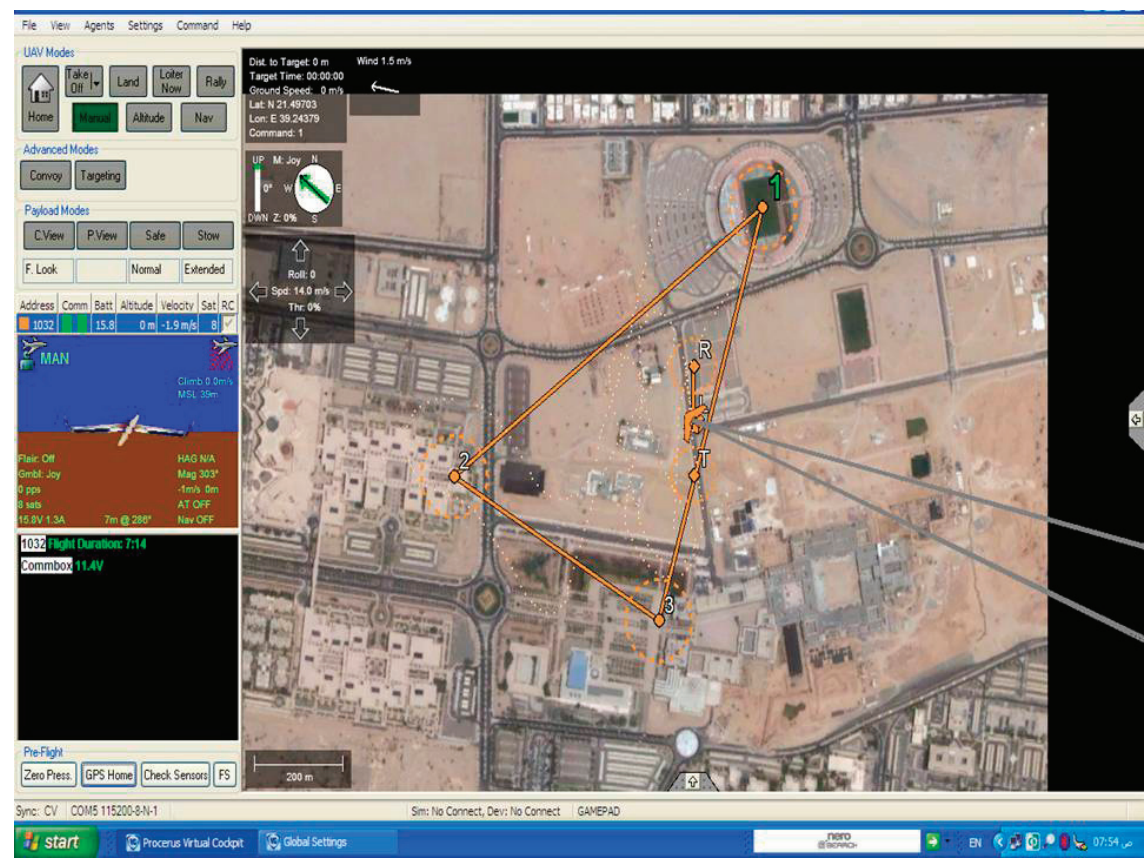

Fig. 11. Procerus virtual cockpit.

\section{Acknowledgements}

The project was fortunate to have the full support of the administration of the College of Engineering and King Abdulaziz University.

\section{References}

[1] Munson, K., Jane's Unmanned Aerial Vehicles and Targets, AMRAes, issue 28 $^{\text {th }}$ May (2007), Jane's information group limited.

[2] Roskam, J., Airplane Design, $2^{\text {nd }}$ Ed. 1989, Roskam Aviation and Engineering Corporation, Ottawa, Kansas. 
[3] www.towerhobbies.com, visited (2008).

[4] Roskam, J., Tau, C. and Lan, E., Airplane Aerodynamics and Performance, DAR Corporation, Lawrence, Kansas ( 1997).

[5] Roskam, J., Airplane Flight Dynamics and Automatic Flight Control, Part I, DAR Corporation, Lawrence, Kansas (1995).

[6] www.procerus.com, visited 2009.

[7] Kestrel Autopilot User Guide, Procerus Technology (2008). 


\section{تصميم وبناء وبرمجة طائرة بدون طيار}

\section{وائل إسماعيل عبدالله هرساني \\ كلية الهندسة، جامعة الملك عبد العزبز -جدة، المدلكة العربية السعودية}

المستخلص. يهدف المشروع إلى تصميم وبناء وبرمجة طائرة غير مأهولة، يتم التحكم فيها ذاتيا دون تدخل خــارجي ( Autonomous (Air Vehicle

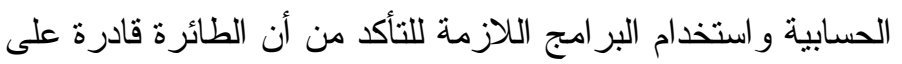

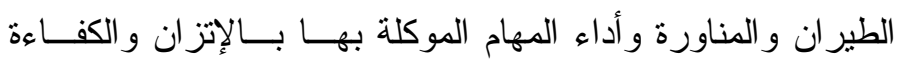

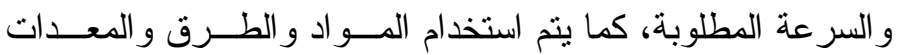
الحديثة في بناء جسم الطائرة. و ينتم أيضا تصميم منظومة طيــار

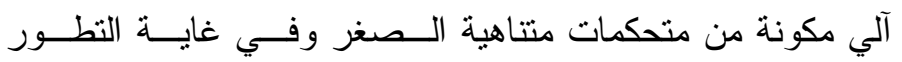

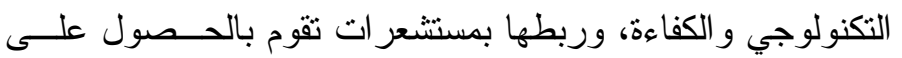

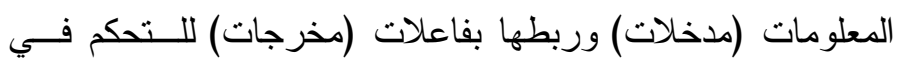

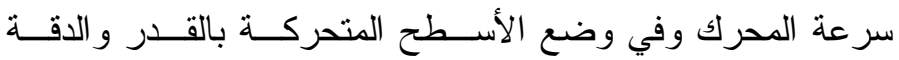

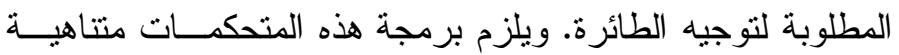

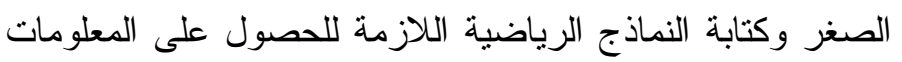

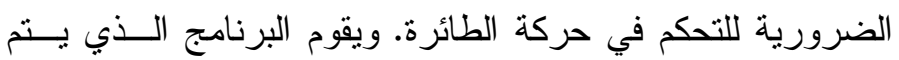

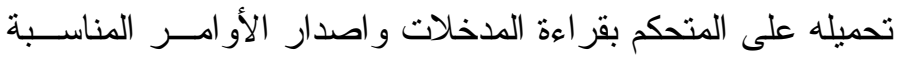

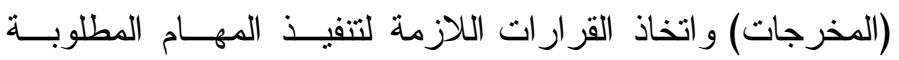
و التحكم في الفاعلات لتوجيه الطائرة بدقة متتاهية للوضع و المكان الجديد المطلوب تو اجدها فيه طبقا للزمن المحدد. 